\title{
Preparation and Characterization of Cinnamon Oil Mediated Gold Nanoparticles and Evaluation of Its Cytotoxicity Using Brine Shrimp Lethality Assay
}

\author{
Rene Jochebed S. ${ }^{1}$, Anitha Roy ${ }^{2}$, Rajeshkumar Shanmugam³ ${ }^{3}$ Devika Warrier E. ${ }^{4}$
}

\begin{abstract}
${ }^{1}$ Department of Pharmacology, Saveetha Dental College and Hospitals, Saveetha Institute of Medical and Technical Sciences, Chennai, Tamil Nadu, India. ${ }^{2}$ Department of Pharmacology, Saveetha Dental College and Hospitals Saveetha Institute of Medical and Technical Sciences, Chennai, Tamil Nadu, India. ${ }^{3}$ Department of Pharmacology, Saveetha Dental College and Hospitals Saveetha Institute of Medical and Technical Sciences, Chennai, Tamil Nadu, India. ${ }^{4}$ Department of Pharmacology, Saveetha Dental College and Hospitals Saveetha Institute of Medical and

Technical Sciences, Chennai, Tamil Nadu, India.
\end{abstract}

\section{ABSTRACT}

\section{BACKGROUND}

Nanotechnology is an emerging science which is associated with the synthesis of nanoparticles mediated with different chemical compositions in variable sizes and its application in health science for human benefit. We wanted to synthesize cinnamon oil mediated gold nanoparticles and evaluate their cytotoxicity using Brine Shrimp Lethality Assay.

\section{METHODS}

$1 \mathrm{~mL}$ of cinnamon oil was dissolved in $9 \mathrm{~mL}$ of distilled water and kept in a beaker. $90 \mathrm{~mL}$ of $1 \mathrm{mM}$ Gold chloride in distilled water was added, mixed and kept in an orbital shaker for nanoparticle synthesis. Color change was noted which indicated the presence of nanoparticles. Preparation of cinnamon oil mediated gold nanoparticles was confirmed using a UV-visible spectrophotometry and the size and shape of the nanoparticles was assessed using Scanning Electron Microscope. Varying concentrations of the synthesized gold nanoparticles was added in separate wells containing live brine shrimp (Artemia salina) and left undisturbed for 24 hours, after which the number of live shrimp larvae was counted in each well to assess the cytotoxicity.

\section{RESULTS}

Cinnamon oil mediated gold nanoparticles were synthesized. Gold nanoparticles were characterized using Scanning Electron Microscope and were $50 \mathrm{~nm}$ in diameter. Brine Shrimp Lethality was done and the cytotoxicity of theses gold nanoparticles was found to be increasing with increasing concentration of the administered gold nanoparticles.

\section{CONCLUSIONS}

The study concludes that evaluating the safety levels is of utmost importance prior to administration of nanoparticles for therapeutic and diagnostic purposes as there was a dose dependent cytotoxicity with cinnamon oil mediated gold nanoparticles.
Corresponding Author:

Dr. Anitha Roy,

Associate Professor,

Department of Pharmacology,

Saveetha Dental College and Hospitals,

Saveetha Institute of Medical and Technical Sciences, ,

Chennai - 77, Tamil Nadu, India

E-mail: anitharoy2015@gmail.com

DOI: $10.14260 / \mathrm{jemds} / 2020 / 633$

How to Cite This Article:

Jochebed RS, Roy A, Shanmugam R, et al. Preparation and characterization of cinnamon oil mediated gold nanoparticles synthesis and evaluation of its cytotoxicity using brine shrimp lethality assay. J Evolution Med Dent Sci 2020;9(39):28942897, DOI: 10.14260/jemds/2020/633

Submission 25-01-2020,

Peer Review 14-08-2020,

Acceptance 20-08-2020,

Published 28-09-2020.

Copyright (C) 2020 Rene Jochebed S et al. This is an open access article distributed under Creative Commons Attribution License [Attribution 4.0 International (CC BY 4.0)]

\section{KEY WORDS}

Cinnamon Oil, Gold Nanoparticles, Cytotoxicity 


\section{BACKGROUND}

Nanotechnology is an emerging science which is associated with the synthesis of nanoparticles mediated with different chemical compositions in variable sizes and its application in health science for human benefit. The use of biological substances like enzymes, plant extracts, micro- organisms, fruit extracts or marine algae is an alternative to chemicals for the synthesis of these nanoparticles. ${ }^{1}$ These nanoparticles are attractive due to the environmental friendly nature of the process.,3 Plants in particular are and excellent source of secondary metabolites and they have been found to be costeffective and eco- friendly for large scale synthesis of nanoparticles. The plant mediated synthesis and characterization of nanoparticles particularly from noble metals like Gold, Silver, Platinum has emerged to be of highly promising.4,5 One of the developments in the recent years is the application of these nanoparticles in modern medicine. The clinical application of nanoparticles ranges from being used as contrast agents in imaging procedures to carriers of drugs for targeted drug delivery. ${ }^{6} \mathrm{~A}$ study conducted by Keerthiga $\mathrm{N}$ et al has revealed that cumin oil mediated silver nanoparticles have potential anti- oxidant activity and that it could be used for targeted drug delivery to improve vascular dysfunction associated with hypertension, diabetes mellitus or atherosclerosis. ${ }^{7}$ Production of nanoparticles under non-toxic green conditions is of vital importance to address the growing concerns on the overall toxicity of nanoparticles for medical and technological applications. ${ }^{8}$ Recently, the preparation of nanoscale gold materials has become very important owing to its unique properties which are different from those of bulk materials. ${ }^{9}$ Gold nanoparticles were synthesised using leaf extracts of Bauhinia tomentosa and quantitative tests confirmed the presence of bioactive phytoconstituents which might be used as a potential agent in cancer therapy. ${ }^{10}$

Cinnamomum verum commonly called as cinnamon, in addition to being easily available, has diverse biological applications which include antibacterial, anti-fungal and antioxidant properties. The physical properties of Cinnamon oil make it a popular choice for air refreshers, aromatherapy and also food flavoring. In the field of medicine, it is used to treat cough, cold, improve digestion and relieve pain. Preliminary findings from laboratory studies show that certain compounds found in cinnamon oil may help destroy Streptococcus mutans which is the primary organism which causes dental caries, promote the widening of blood vessels which may aid in the treatment of blood pressure and regulates blood pressure thereby helping in the management of Diabetes. ${ }^{10}$ However, because of the strong nature of cinnamon, if used in excess it can cause rashes and discomfort if applied topically and hence it is always instructed to be used after dilution. In the field on nanotechnology, Cinnamon mediated silver nanoparticles were found to possess antibacterial activity against E. coli. ${ }^{11}$

The advantages of noble metal-based nanoparticles include high biocompatibility and stability. Ginger mediated silver nanoparticles were synthesised and were found to possess anti-bacterial activity against Streptococcus mutans which is a common oral pathogen. ${ }^{12}$ The first study involving gold nanoparticles was done in 1971 by the British researchers Faulk and Taylor. ${ }^{13}$ Various naturally occurring compounds like Olive leaves, Allium cepa, Terminalia catappa have been used for the production of gold nanoparticles and to study its applications. Gold nanoparticles are utilized in many ways which include immunochemical studies, detection of protein interactions and detection of DNA in a fingerprint sample. ${ }^{14}$ despite, the useful nature of these nanoparticles, evaluating the safety dosage and estimating dosage levels is of prime importance. Brine Shrimp Lethality Assay (BSLA) has been used to screen the toxicity of plant extracts, heavy metal and metal ion toxicity, cyanobacteria, nanoparticles and marine natural products as an alternative to bioassay technique. We wanted to synthesize cinnamon oil mediated gold nanoparticles and evaluate their cytotoxicity using Brine Shrimp Lethality Assay.

\section{METHODS}

\section{Preparation of Gold Nanoparticles Using Cinnamon Oil}

$1 \mathrm{~mL}$ of cinnamon oil was dissolved in $9 \mathrm{~mL}$ of distilled water and kept in a beaker. $90 \mathrm{~mL}$ of $1 \mathrm{mM}$ Gold chloride in distilled water was added and mixed and kept in a boiling water bath for 30- 60 minutes. The solution was then kept in an orbital shaker for nanoparticle synthesis. The color change was observed and recorded periodically and photographs were taken.

\section{Characterization of Nanoparticles - UV-Visible Spectrophotometric Analysis of Gold Nanoparticles \\ The synthesized nanoparticles was preliminarily characterized using an UV- visible spectroscopy. $3 \mathrm{~mL}$ of the synthesized nanoparticle solution was taken in a cuvette and scanned in double beam UV visual spectrophotometer from 400-650 nm wavelength. The results were recorded and graphical analysis was done. The prepared cinnamon oil mediated gold nanoparticle solution was then morphologically analyzed using a scanning electron microscope.}

\section{Brine Shrimp Lethality Assay}

Newly hatched Brine Shrimp (Artemia salina) larvae (Nauplii) was taken 10 and were transferred into 5 wells. The synthesized cinnamon oil mediated Gold nanoparticles were introduced into each of the wells of varying concentrations of $20,40,60,80$ and $100 \mu \mathrm{L}$. One well with live nauplii was without the Gold nanoparticles and it served as the standard sample. The samples were left undisturbed for 24 hours. The number of live nauplii after 24 hours was noted and the data was plotted in the form of a graph.

\section{RESULTS}

Cinnamon oil mediated gold nanoparticles were synthesized. This was indicated by the color of the solution which changed to a greyish white colour within 1 hour of reaction with the Gold chloride solution. The appearance of greyish white colour indicated the formation of gold nanoparticles. The intensity of the colour gradually increased with time of incubation. Production of gold nanoparticles was seen maximum at a wavelength of $525 \mathrm{~nm}$ as viewed in a spectrophotometer and 
the data was plotted in a graph. The SEM images showed the formation of spherical shaped nanoparticles. The SEM images of Cinnamon oil mediated Gold nanoparticles are shown in the figure 1 . The size of the nanoparticles was mostly uniform about $50 \mathrm{~nm}$. (Figure 1). ${ }^{15}$ The synthesized gold nanoparticles was then evaluated for its cytotoxicity using Brine Shrimp Lethality Assay. The nauplii were exposed to different concentrations $(20,40,60,80$ and 100 microliters $)$ of cinnamon oil mediated gold nanoparticles and left undisturbed for a time period of 24 hours. The number of live nauplii alive after 24 hours in each well inoculated with various concentrations of Gold nanoparticles was noted for determining the level of cytotoxicity and a chart was formulated (Figure 4). The number of live nauplii was highest in the well where $20 \mu \mathrm{L}$ of the synthesized gold nanoparticle was administered and lowest in the well where a concentration of $100 \mu \mathrm{L}$ was administered.

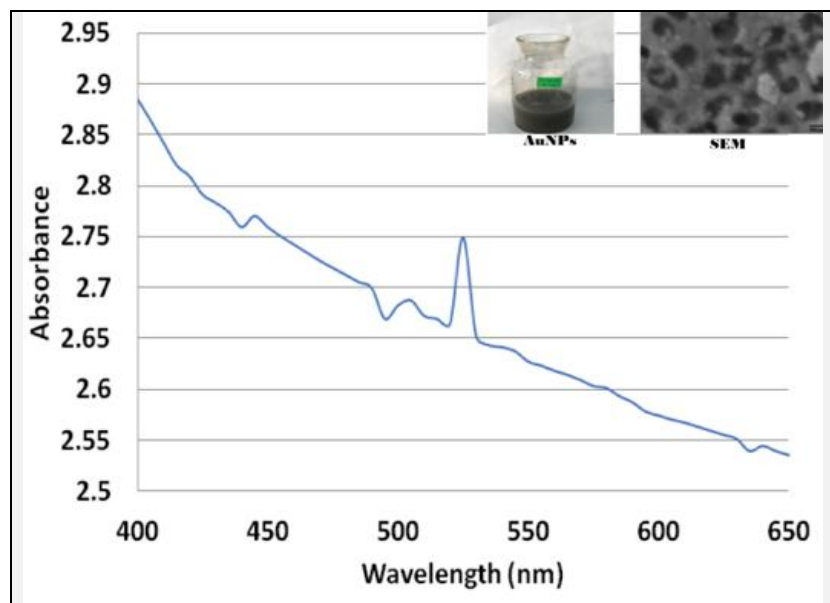

Graph 1. UV-Visible Spectroscopic Analysis of Cinnamon Oil Mediated Gold Nanoparticles and Colour Change and SEM

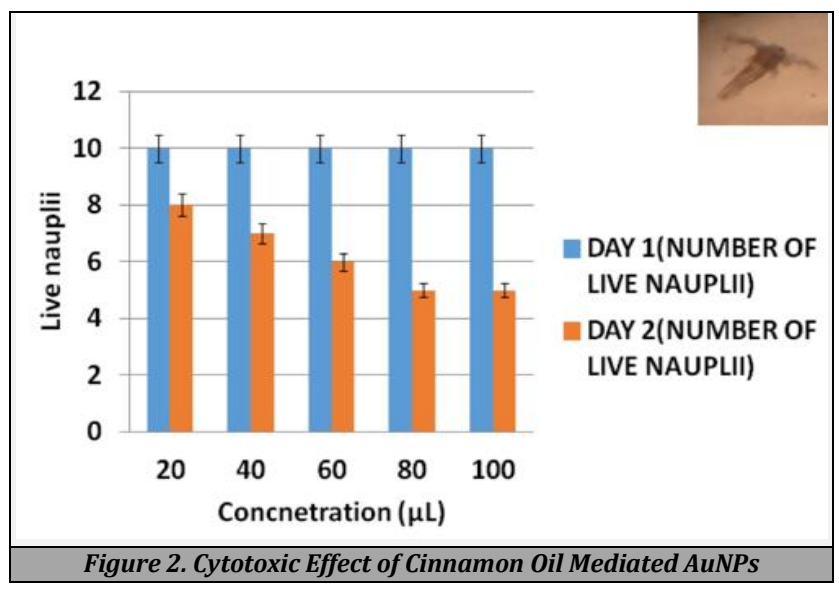

\section{DISCUSSION}

UV- visible spectroscopy is used routinely for the quantitative determination of metal ions, organic compounds and biological molecules. The formation of gold nanoparticles was confirmed by colour changes followed by UV- Visible spectrophotometer analysis at room temperature. It was observed from the spectra that the gold nanoparticles resonance peak occurs at $525 \mathrm{~nm}$. This confirms the formation of gold nanoparticles. The microstructure and the size of the biosynthesised gold nanoparticles was assessed using Scanning Electron Microscope.

In a study done by Cibikkarthik et al, avocado seed extract mediated silver nanoparticle was found to possess good antibacterial effect against gram positive and gram- negative organisms. ${ }^{16}$ In another study done by S. Vignesh et al, cumin mediated silver nanoparticles was found to inhibit certain micro- organisms in a dose- dependent manner. ${ }^{17}$ All these researches have pointed out the effects of naturally synthesised nanoparticles. The diverse beneficial properties of these plant mediated nanoparticles bring in the question of safety dosages and limits. All plant extracts, fractions, nanoparticles and pure compounds isolated in phytochemical laboratories should be submitted to as wide a range of bioassays as possible. ${ }^{18}$

Brine Shrimp lethality assay is an important tool for the preliminary cytotoxicity assay of plant extract depending on its ability to kill a laboratory cultured larvae (nauplii). It is a simple, cost- effective method and requires small amount of test material. The most commonly used organism in Brine Shrimp Lethality Assay is Artemia salina.${ }^{19}$ In the presence of salt solution $(2 \%-4 \%)$, the shrimp eggs hatch into larvae (nauplii). Seawater is recommended for this purpose. If not available, distilled water with sea salt can be used. Tap water is not recommended for this as it contains chlorine. The ideal $\mathrm{pH}$ is 8.0+/- 0.5 which is adjusted using Sodium hydroxide or Sodium carbonate. At room temperature, the nauplii hatch within 20-30 hours. During the study period, the nauplii do not receive any food. The death of the nauplii may be due to the effect of the inoculated substance of starvation. To ensure the mortality effect of the subject under study, a control sample containing nauplii without inoculation of the study substance is used. The nauplii can survive for up to 48 hours without food because they still fed on their yolk sac. Brine Shrimp Lethality Assay indicates that the number of live Shrimp larvae at higher concentrations was lesser when compared to lower concentrations, and as the concentration of the Gold nanoparticles increased, the cytotoxicity was also increased which resulted in lesser number shrimp larvae which were still alive after 24 hours.

\section{CONCLUSIONS}

Preparation of cinnamon oil mediated gold nanoparticles with gold chloride was demonstrated. The formation of gold nanoparticles was confirmed by colour changes and UV spectrophotometer. The UV visible spectrum showed a broad peak located at $525 \mathrm{~nm}$. The size as determined by Scanning Electron Microscope was $50 \mathrm{~nm}$. The shape of the gold nanoparticles was spherical. Cytotoxicity evaluation using Brine Shrimp Lethality assay showed that higher the concentration, higher is the cytotoxicity of the gold nanoparticles. Considering this, the amount of gold nanoparticles has to be evaluated prior to administration, for therapeutic or diagnostic purposes and safety dosage levels have to be established

Financial or Other Competing Interests: None. 


\section{REFERENCES}

[1] Daisy P, Saipriya K. Biochemical analysis of cassia fistula aqueous extract and photochemically synthesised gold nanoparticles as hypoglycaemic treatment for diabetes mellitus. Int J Nanomedicine 2012;7:1189-202.

[2] Smitha SL, Philip D, Gopchandran KG. Green synthesis of gold nanoparticles using Cinnamomum zeylancium leaf broth. Spectrochim Acta A Mol Biomol Spectrosc 2009;74(3):735-9.

[3] Narayanan KB, Sakthivel N. Coriander leaf mediated biosynthesis of gold nanoparticles. Materials Letters 2008;62(30):4588-90.

[4] Zhan G, Hunag J, Lin L, et al. Synthesis of gold nanoparticles by Cacumen Platycladi leaf extract and its simulated solution: toward the plant mediated biosynthetic mechanism. Journal of Nanoparticle Research 2011;13(10):4957-68.

[5] Petla RK, Vivekanandan S, Misra M, et al. Soybean (Glycine max) leaf extract based green synthesis of Palladium nano particles. Journal of Biomaterials and Nanobiotechnology 2012;3:14-9.

[6] Song JY, Jang HK, Kim BS. Biological synthesis of gold nanoparticles using Magnolia kobus and Diopyros kaki leaf extracts. Process Biochemistry 2009;44(10):1133-8.

[7] Keerthiga N, Anitha R, Rajeshkumar S, et al. Antioxidant activity of cumin oil mediated silver nanoparticles. Pharmacognosy Journal 2019;11(4):787-9.

[8] Parida UK, Bindhani BK, Nayak P. Green synthesis and characterisation of gold nanoparticles using onion (Allium сера) extract. World Journal of Nano Science and Engineering 2011;1(4):93-8.

[9] Nagaraj B, Krishnamurthy NB, Liny P, et al. Biosynthesis if gold nanoparticles of ixora coccinea flower extract \& their antimicrobial activities. International Journal of Pharma and Bio Sciences 2011;2(4):557-65.
[10] Mukundan D, Mohankumar R, Vasanthakumari R. Green synthesis of gold nanoparticles using leaves extra of Bauhinia tomentosa Linn and in vitro anticancer activity. International Journal of Innovative Research in Science \& Engineering 2005.

[11] Abdalla KH, Al-Hannan F, Alghamdi A, et al. Green synthesis of silver nanoparticles using cinnamon (Cinnamon cassia), characterisation and antibacterial activity. International Journal of Science and Research 2017;6(6):965-71.

[12] Gayathri K, Roy A, Lakshmi T, et al. Controlling of oral pathogens using ginger oleoresin mediated silver nanoparticles. International Journal of Research in Pharmaceutical Sciences 2019;10(4):2988-91.

[13] Dykman LA, Khlebtsov NG. Gold nanoparticles in biology and medicine: recent advances and prospects. Acta Naturae 2011;3(2):34-55.

[14] Krishnia NR, Gayathri R, Priya V. Nanoparticles and their applications - a review. J Pharm Sci Res 2017;9(1):24-7.

[15] Sarah QS, Anny FC, Misbahuddin M. Brine shrimp lethality assay. Bangladesh Journal of Pharmacology 2017;12:1869.

[16] Cibikkarthik T, Rajeshkumar S, Lakshmi T, et al. Antiinflammatory activity of avocado seed extract mediated silver nanoparticles. Drug Invention Today 2019;12(9):2077-80.

[17] Vignesh S, Roy A, Kumar SR, et al. Evaluation of the antimicrobial activity of cumin oil mediated silver nanoparticles on oral microbes. Research Journal of Pharmacy and Technology 2018;12(8):3709-12.

[18] Montanher ABP, Pizzolatti MG, Brihente IMC. An application of the brine shrimp bioassay for general screening of Brazilian medicinal plants. Acta Farm Bonarense 2002;21(3):175-8.

[19] Hamidi MR, Jovanova B, Panovska TK. Toxological evaluation of the plant products using brine shrimp (Artemia salina L.) model. Macedonian Pharmaceutical Bulletin 2014;6(1):9-18. 